\title{
Chemical Looping Pilot Plant Results Using a Nickel-Based Oxygen Carrier
}

\author{
T. Pröll*, P. Kolbitsch, J. Bolhàr-Nordenkampf and H. Hofbaver \\ Vienna University of Technology, Institute of Chemical Engineering, Getreidemarkt 9/166, Vienna 1060 - Austria \\ e-mail: tobias.proell@tuwien.ac.at - philipp.kolbitsch@gmx.at - hermann.hofbaver@tuwien.ac.at \\ * Corresponding author
}

\begin{abstract}
Résumé - Résultats de l'expérimentation sur un pilote opérant en boucle chimique avec un matériau transporteur d'oxygène à base de nickel - Un pilote d'étude de la combustion en boucle chimique d'une puissance thermique de $120 \mathrm{~kW}$ a été dimensionné, construit et opéré. Il est constitué de deux lits circulants interconnectés. Les résultats d'opération qui sont présentés ont été obtenus avec un matériau transporteur d'oxygène très réactif à base de nickel. L'inventaire total du matériau est de $65 \mathrm{~kg}$ dans le pilote. La conversion du méthane atteinte est voisine de $99,8 \%$ et le rendement en $\mathrm{CO}_{2}$ est de $92 \%$. Lorsqu'on opère en mode de reformage, l'équilibre thermodynamique est atteint dans le réacteur fioul. Tout l'oxygène est capté dans le réacteur air dès que le rapport stoechiométrique entre l'air et le méthane est inférieur à 1 et que la température est supérieure à $900^{\circ} \mathrm{C}$. Aucune formation de carbone à la surface des particules n'a été mise en évidence si le rapport stoechiométrique entre l'air et le méthane est supérieur à 0,4, alors que la charge gazeuse $\left(98,6 \%\right.$ vol. $\left.\mathrm{CH}_{4}\right)$ est injectée dans le réacteur fioul sans addition de vapeur. À partir de l'état de l'art et de ces résultats, il est conclu que des applications telles que la production de vapeur ou la production couplée d'azote ou d'hydrogène sont des voies intéressantes à considérer pour l'extrapolation de la technologie.
\end{abstract}

Abstract - Chemical Looping Pilot Plant Results Using a Nickel-Based Oxygen Carrier - A chemical looping pilot plant was designed, built and operated with a design fuel power of $120 \mathrm{~kW}$ (lower heating value, natural gas). The system consists of two Circulating Fluidized Bed (CFB) reactors. Operating results are presented and evaluated for a highly reactive nickel-based oxygen carrier, total system inventory $65 \mathrm{~kg}$. The performance in fuel conversion achieved is in the range of $99.8 \%\left(\mathrm{CH}_{4}\right.$ conversion) and $92 \%\left(\mathrm{CO}_{2}\right.$ yield). In chemical looping reforming operation, it can be reported that thermodynamic equilibrium is reached in the fuel reactor and that all oxygen is absorbed in the air reactor as soon as the global stoichiometric airlfuel ratio is below 1 and the air reactor temperature is $900^{\circ} \mathrm{C}$ or more. Even though pure natural gas (98.6 vol.\% $\mathrm{CH}_{4}$ ) without steam addition was fed to the fuel reactor, no carbon formation has been found as long as the global stoichiometric airlfuel ratio was larger than 0.4. Based on the experimental findings and on the general state of the art, it is concluded that niche applications such as industrial steam generation from natural gas or $\mathrm{CO}_{2}$-ready coupled production of $\mathrm{H}_{2}$ and $\mathrm{N}_{2}$ can be interesting pathways for immediate scale-up of the technology. 


\section{NOTATION}

$\begin{array}{ll}G_{s} & \text { Solids flux }\left(\mathrm{kg} \cdot \mathrm{m}^{-2} \mathrm{~s}^{-1}\right) \\ m & \text { Mass }(\mathrm{kg}) \\ \dot{m} & \text { Mass flow }\left(\mathrm{kg} \cdot \mathrm{s}^{-1}\right) \\ P_{t h} & \text { Fuel power }(\text { lower heating value })(\mathrm{W}) \\ T & \text { Temperature }(\mathrm{K}) \\ X_{s} & \text { Solids degree of oxidation (-) } \\ y & \left.\text { Mole fraction in gas phase (mol.mol }{ }^{-1}\right)\end{array}$

\section{Greek symbols}

$\gamma \quad$ Chemical yield (-)

$\Delta \quad$ Symbolizes difference (-)

\section{Indices}

$\begin{array}{ll}\text { AR } & \text { Air Reactor } \\ \text { FR } & \text { Fuel Reactor } \\ \text { LLS } & \text { Lower Loop Seal (from FR to AR) } \\ \text { red } & \text { Refers to fully reduced particles } \\ \text { ox } & \text { Refers to fully oxidized particles } \\ \text { ULS } & \text { Upper Loop Seal (from AR to FR) }\end{array}$

\section{INTRODUCTION}

Carbon capture and storage is discussed as the key mid-term strategy to limit $\mathrm{CO}_{2}$ emissions to the atmosphere. The three most popular approaches towards carbon capture require gasgas separation steps: either $\mathrm{CO}_{2}$ separation (pre- and postcombustion capture) or $\mathrm{O}_{2}$ separation from air (oxyfuel combustion). Chemical Looping Combustion (CLC), however, is an unmixed combustion technology [1] where energy-intensive gas-gas separation is inherently avoided. In CLC, a solid oxygen carrier is used to selectively transport oxygen from an Air Reactor (AR) to a Fuel Reactor (FR). If a suitable metal oxide system is chosen, full oxidation of the fuel to $\mathrm{CO}_{2}$ and $\mathrm{H}_{2} \mathrm{O}$ is possible in the FR. Therefore, CLC shows a unique potential for carbon capture and has witnessed increasing scientific interest in recent years [2]. A variant of CLC where less oxygen is provided than needed for full oxidation of the fuel is Chemical Looping Reforming (CLR). In CLR, a synthesis gas is obtained from the FR.

Dual fluidized bed reactor systems came up along with the establishment of fluid catalytic cracking units in the middle of the 20th century. Full oxidation of the fuel to $\mathrm{CO}_{2}$ and $\mathrm{H}_{2} \mathrm{O}$ using $\mathrm{CuO}$ as oxygen carrier was first proposed by Lewis and Gilliland in a patent application filed in 1951 [3]. The possibility of selectively transporting oxygen for partial oxidation of hydrocarbons, i.e. CLR, was proposed by Welty already before, in 1946 [4]. Since more $\mathrm{CO}_{2}$ occurs as a by-product in industrial processes than needed as a commodity in industry, no further development of the full conversion idea took place apart from some theoretical considerations to improve reversibility of combustion in the 1960-ies [5]. Ishida and co-workers were the first to propose CLC as a technology to capture $\mathrm{CO}_{2}$ for sequestration [6]. Therefore, CLC witnessed increasing attention since about the year 2000. While most of the worldwide research is focused on development of suitable oxygen carrier particles, some groups have developed laboratory and bench scale units for continuous testing [7-10].

This article represents the conclusion of the first experimental campaign carried out at a chemical looping pilot plant in Vienna. A nickel-based oxygen carrier was used during these experiments. Both the design of the pilot unit and the main results have already been presented in a number of publications [11-17]. The focus of the present paper is, therefore, to add some previously undisclosed data and points of discussion. The effect of the staged introduction of air into the AR is discussed for CLC and the gap to CLR operation is bridged.

\section{THEORETICAL BACKGROUND}

\subsection{Chemical Reactions in CLC and CLR}

In order to provide a reference for the discussion of results below, the most relevant chemical reactions for CLC and CLR are briefly introduced. In the AR, the oxygen carrier is oxidized in contact with free $\mathrm{O}_{2}$ from the supplied air stream (R1).

$$
\mathrm{MeO}_{\alpha-1}+\frac{1}{2} \mathrm{O}_{2} \rightarrow \mathrm{MeO}_{\alpha}
$$

This is a single step reaction and in the case of nickel as the metal (Me) in R1, equilibrium $\mathrm{O}_{2}$ partial pressures at typical operating temperatures are very low $\left(\sim 10^{-12}\right.$ bar at $\left.900^{\circ} \mathrm{C}\right)$. Thus, in case of limited air supply typical for CLR, quantitative absorption of $\mathrm{O}_{2}$ is thermodynamically possible. Reaction R1 is always strongly exothermal.

In the FR, the oxygen carrier is reduced and hydrocarbon fuel is oxidized. This happens as a combination of various reactions and can be described by the following reactions (selection of those believed to be of importance in CLC and CLR).

Partial oxidation of the fuel by the oxygen carrier (R2):

$$
\mathrm{C}_{x} \mathrm{H}_{y}+x \mathrm{MeO}_{\alpha} \leftrightarrow x \mathrm{CO}+\frac{y}{2} \mathrm{H}_{2}+x \mathrm{MeO}_{\alpha-1}
$$

Oxidation of $\mathrm{CO}$ and $\mathrm{H}_{2}$ by the oxygen carrier $(\mathrm{R} 3, \mathrm{R} 4)$ :

$$
\mathrm{CO}+\mathrm{MeO}_{\alpha} \leftrightarrow \mathrm{CO}_{2}+\mathrm{MeO}_{\alpha-1}
$$




$$
\mathrm{H}_{2}+\mathrm{MeO}_{\alpha} \leftrightarrow \mathrm{H}_{2} \mathrm{O}+\mathrm{MeO}_{\alpha-1}
$$

Steam reforming of hydrocarbons (R5):

$$
\mathrm{C}_{x} \mathrm{H}_{y}+x \mathrm{H}_{2} \mathrm{O} \stackrel{\text { cat. }}{\longrightarrow} x \mathrm{CO}+\left(x+\frac{y}{2}\right) \mathrm{H}_{2}
$$

Water-gas shift (CO shift) reaction (R6):

$$
\mathrm{CO}+\mathrm{H}_{2} \mathrm{O} \stackrel{\text { cat. }}{\longrightarrow} \mathrm{CO}_{2}+\mathrm{H}_{2}
$$

Reactions R5 and R6 are known to be significantly catalyzed by metallic surfaces at the typical operating temperatures of CLC and CLR.

Formally, reactions R2-R4 would be sufficient to describe full oxidation of fuel to $\mathrm{CO}_{2}$ and $\mathrm{H}_{2} \mathrm{O}$. Reactions R5 and R6 are expected to happen especially if steam and free nickel surfaces are available. Typically, the FR exhaust gas composition reflects equilibrium of the $\mathrm{CO}$ shift reaction (R6).

If the fuel is a hydrocarbon and nickel-based oxygen carriers are used, the FR overall reaction is always endothermal. The energy requirement is lowest for the ideal case of full oxidation of the fuel and increases if increasing amounts of $\mathrm{CO}$ and $\mathrm{H}_{2}$ occur as a consequence of incomplete oxidation. This is relevant for CLR, where a decrease in oxygen consumption goes along with an increased need for heat in the FR.

With respect to thermodynamics, hydrocarbons are not stable at typical operating conditions of CLC and CLR. At atmospheric pressure and typical elementary compositions, the most stable hydrocarbon compound $\mathrm{CH}_{4}$ is not present any more in equilibrium for temperatures above $750^{\circ} \mathrm{C}$. In CLC, where the amount of oxygen carrier available in the FR is not limiting, thermodynamic equilibrium can be approximated by full conversion according to reaction R2 and equilibrium of reactions R3 and R4 determining residual amounts of $\mathrm{CO}$ and $\mathrm{H}_{2}$ in the FR exhaust gas. Figure 1 shows the reachable minimum concentrations of $\mathrm{CO}$ and $\mathrm{H}_{2}$ for different oxygen carrier systems for a typical case with pure $\mathrm{CH}_{4}$ as FR feed. Thus, the $\mathrm{Ni} / \mathrm{NiO}$ system is not optimal from the thermodynamic perspective. High reactivity, especially with respect to hydrocarbon conversion, however, makes Ni-based oxygen carriers reach higher fuel conversion performances in continuous operation compared to the other known systems.

\subsection{Overall System Behavior}

$\mathrm{AR}$ and FR of chemical looping systems are strongly interlinked through the circulating solids stream. Besides the selective transport of oxygen from the AR to the FR, also heat is transported. At reasonable solids circulation rates the temperature difference between AR and FR is typically below $100 \mathrm{~K}$ [18]. In CLC, the total amount of heat released

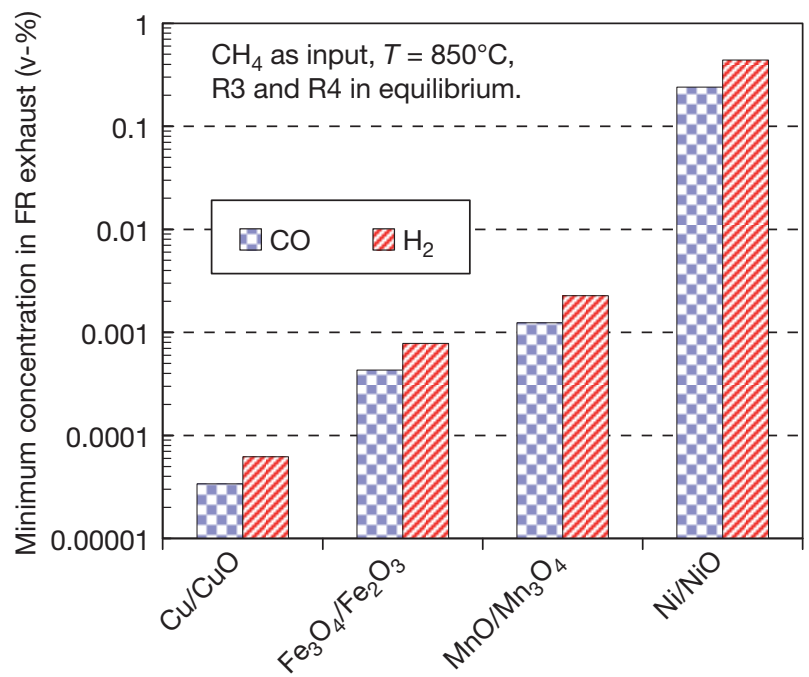

Figure 1

Residual concentration of $\mathrm{CO}$ and $\mathrm{H}_{2}$ in the Fuel Reactor (FR) exhaust gas stream in thermodynamic equilibrium [18].

is equal to that of direct combustion. Therefore, at global stoichiometric air supply about $60 \%$ of the released heat must be withdrawn directly from the reactor system to keep the required operating temperature [18]. In CLR operation, less heat is released due to incomplete oxidation and adiabatic operation is reached at a certain global air/fuel ratio [18].

The average degree of oxidation of the oxygen carrier particles in the system is the result of a dynamic equilibrium defined by the global air/fuel ratio operated and by the conversion efficiency in AR and FR, respectively. The conversion efficiency depends on the specific solids inventory, the reactivity of the oxygen carrier, and on the quality of gassolid contact in the reactor. If, as in some laboratory units, the AR is very large, the particles are practically fully oxidized when leaving the AR in CLC operation. If the reactors are, however, designed to contain only the amount of solids necessary for conversion of the gas phase, full conversion of solids is neither achieved nor necessary [15].

\subsection{The Dual Circulating Fluidized Bed (DCFB) Concept}

Since good gas-solid contact and high solids transport rates between the reactors are very important in CLC, the AR and FR are typically designed as fluidized bed reactors. Lyngfelt et al. [19] have proposed a reactor system that consists of a fast fluidized bed AR and a Bubbling Fluidized Bed (BFB) FR. A very similar design is described by Ryu et al. [20]. In contrast to this design, the DCFB reactor system (Fig. 2) features a circulating fluidized bed FR. The global solids loop starts in the AR where solids are entrained, separated from the gas in a cyclone and sent to the FR via a fluidized loop seal. From the FR, the solids are flowing back into the AR 
via a second loop seal connecting the bottom regions of the two reactors. The FR features a circulation loop in itself (FR cyclone and loop seal) and may be optimized with respect to good gas-solid contact and low particle attrition. The direct hydraulic communication of the two circulating fluidized bed reactors via the lower loop seal results in a stable solids distribution in the system. This way, the bypass of fuel in the bubble phase is reduced. A more detailed discussion of the DCFB system has been recently published [15].

\section{EXPERIMENTAL}

The pilot plant used for the present study is designed according to Figure 1 with an AR $4.1 \mathrm{~m}$ high, $0.15 \mathrm{~m}$ inner diameter and a FR $3.0 \mathrm{~m}$ high, $0.16 \mathrm{~m}$ inner diameter. The AR is equipped with a variable cooling system in order to control the temperature independently of the global air/fuel ratio operated. The cyclone separators are designed according to Hugi and Reh [21]. Apart from natural gas from the grid (98.7 vol.\% $\mathrm{CH}_{4}$ ), the unit can be operated with artificial gas mixtures from gas cylinders stacks. The loop seals are fluidized with steam in nominal operation and may be switched to air fluidization during startup and shutdown. The exhaust gas streams of the two reactors are cooled separately to about $300^{\circ} \mathrm{C}$ and analyzed online to evaluate the conversion of the fuel as well as the leakages of the loop seals. For the FR

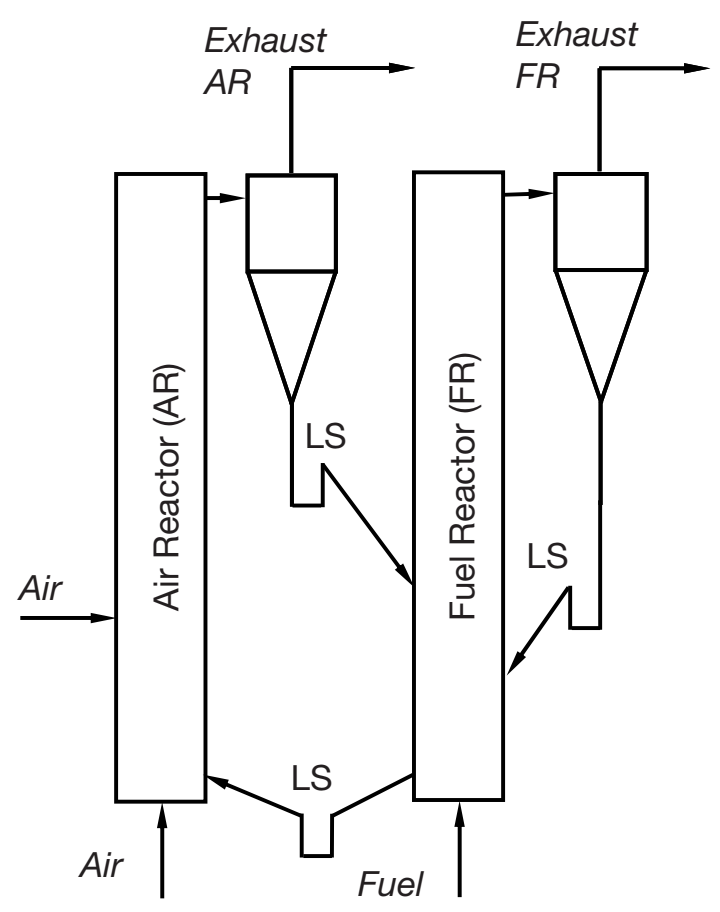

Figure 2

The Dual Circulating Fluidized Bed (DCFB) reactor concept for chemical looping processes (LS - loop seal fluidized with steam). exhaust gas composition, a Rosemount NGA 2000 (CO: 0$100 \%, \mathrm{CO}_{2}: 0-100 \%, \mathrm{O}_{2}: 0-25 \%, \mathrm{H}_{2}: 0-100 \%, \mathrm{CH}_{4}: 0-100 \%$ ) is used and, additionally, an online gas chromatograph Syntech Spectras GC 955, which allows cross-checking of carbon species and determination of the $\mathrm{N}_{2}$ content for evaluation of possible gas leakages from the AR to the FR. The AR exhaust stream is analyzed using a Rosemount NGA 2000 (CO: 0-100\%, $\mathrm{CO}_{2}: 0-100 \%, \mathrm{O}_{2}: 0-25 \%$ ). The cooled exhaust gas streams pass valves which make it possible to impose a defined backpressure on each reactor. The exhaust gas streams are then mixed and sent to a natural gas-fired post combustion unit, cooled again, cleaned in a bag filter, and sent to the chimney. Solids sampling is possible out of the upper and the lower loop seal during operation. This allows accurate interpretation of experimental results (degree of oxidation of carrier and solids circulation rate) [13]. The plant is operated and monitored using computer-integrated process control. The flow rates of the two fluidizing air streams and the fuel stream are measured and controlled using rotary instruments (Elster Instromet $R V G$ ) in combination with electrical control valves. The steam flow rates to the loop seals are measured using industrial steam flow meters (Krohne H250/RR/M9). Temperature and system pressure are measured online at 30 positions. Pressure measurements allow online determination of the actual solids inventory in each reactor. For safe handling of potentially hazardous solids, a portable lock is used in combination with pneumatic transport lines.

The fuel used in all the experiments presented is natural gas. No extra steam was added to the fuel except the steam used for loop seal fluidization. A 50:50 (weight based) mixture of two designed NiO-based oxygen carriers is used in all the runs presented. Overall, the particles show an active $\mathrm{NiO}$ content of $40 \mathrm{wt} . \%$ and a mean particle size of $135 \mu \mathrm{m}$. The oxygen carrier mixture is described in detail by Linderholm et al. [22].

In the CLC experiments presented, the air introduction into the AR was shifted from the lower (standard) level partly to an upper level (air staging). This is expected to result in decreased global solids circulation rates. All other parameters like fuel load (140 kW), global air/fuel ratio (1.1) and the FR temperature $\left(900^{\circ} \mathrm{C}\right)$ are kept constant. The relevant performance parameters in CLC operation are the $\mathrm{CH}_{4}$ conversion $X_{\mathrm{CH}_{4}}$ according to

$$
X_{\mathrm{CH}_{4}}=1-\left.\frac{y_{\mathrm{CH}_{4}}}{y_{\mathrm{CO}_{2}}+y_{\mathrm{CO}}+y_{\mathrm{CH}_{4}}}\right|_{\text {Fuel Reactor exhaust }}
$$

where $y$ represent gas phase mole fractions, and the $\mathrm{CO}_{2}$ yield $\gamma_{\mathrm{CO}_{2}}$, which is defined by:

$$
\gamma_{\mathrm{CO}_{2}}=\left.\frac{y_{\mathrm{CO}_{2}}}{y_{\mathrm{CO}_{2}}+y_{\mathrm{CO}}+y_{\mathrm{CH}_{4}}}\right|_{\text {Fuel Reactor exhaust }}
$$


It is important to notice that Equations (1) and (2) can only be applied if $\mathrm{CH}_{4}$ is the only carbon containing species fed to the FR and if carbon loss to the AR can be excluded.

The degree of oxidation of the oxygen carrier particles is defined according to:

$$
X_{s}=\frac{m-m_{r e d}}{m_{o x}-m_{r e d}}
$$

where $m$ is the mass of the sample and $m_{o x}$ and $m_{\text {red }}$ refer to the mass of the sample in fully oxidized and in fully reduced state, respectively. This means that $X_{s}$ is equal to zero in the fully reduced state and equal to one in the fully oxidized state.

In the CLR experiments presented, a variation of the global stoichiometric air/fuel ratio was carried out at a constant FR temperature of $900^{\circ} \mathrm{C}$ and at a constant fuel power of $140 \mathrm{~kW}_{\text {th }}$.

\section{RESULTS AND DISCUSSION}

\subsection{Chemical Looping Combustion}

Figure 3 shows the solids circulation rate and the degree of oxidation of the particles in both loop seals connecting the two reactors. As mentioned above, it is expected that the solids circulation rate goes down when a larger part of the air is introduced in the upper stage. However, the effect of air staging on the global solids circulation rate turns out to be not as pronounced as predicted by the cold flow model [12]. A possible explanation here is, that the gas velocity in the AR is already rather high at the $140 \mathrm{~kW}$ load point and material is easily lifted up to the second air level. Also, the contact of gas and solids in the AR is influenced by air staging and thus a lower global degree of oxidation of the particles is expected for operation with part of the air introduced at the upper level. This is generally the case according to Figure 3. It is important to note that the degree of oxidation was generally relatively low during this run, also compared to other experiments carried out under comparable conditions, where values around 0.5 have been found $[14,15]$. The reason for this different behavior is not entirely understood. It practically depended on the short-term "history" of the unit, i.e. whether it was operated at reforming conditions before or not. For the situation presented here, the unit was operated in CLR mode before the CLC test campaign whereas the runs reported in [15] were done right after start up, where the particles were fully oxidized at the beginning. It is important to note that the operating points presented were kept for a steady operating time between 30 and 60 minutes before the data were taken.

The corresponding fuel conversion performance is shown in Figure 4. The plot shows the total amount of carbon divided in $\mathrm{CO}_{2}$ (below the $\gamma_{\mathrm{CO}_{2}}$ line), $\mathrm{CH}_{4}$ (above the $X_{\mathrm{CH}_{4}}$ line) and $\mathrm{CO}$ (between the lines). The $\mathrm{H}_{2}$ concentration in the FR exhaust, also measured, turns out to obey to the equilibrium of the CO-shift reaction R6. In the CLC conditions presented here, this means $\mathrm{H}_{2}$ is present with roughly double the concentration of $\mathrm{CO}$.

It turns out that the methane conversion is high, at least compared to previous results reported for this pilot plant. The methane conversion tends to decrease with increasing solids circulation or increasing degree of oxidation, respectively.

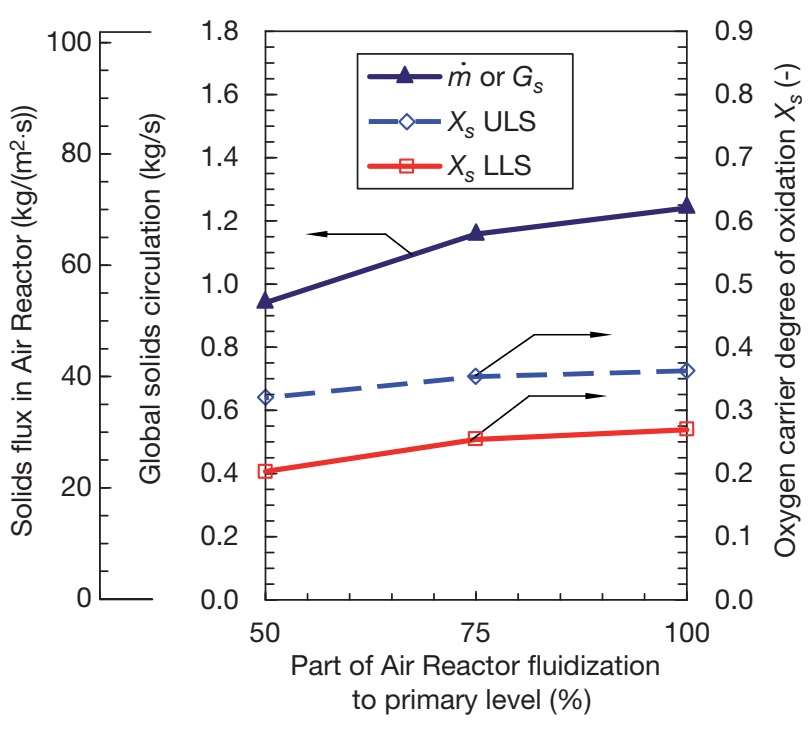

Figure 3

Solids circulation rate and oxygen carrier degree of oxidation during variation of Air Reactor fluidization level (ULS $=$ Upper Loop Seal, AR $\rightarrow$ FR; LLS = Lower Loop Seal, FR $\rightarrow$ AR).

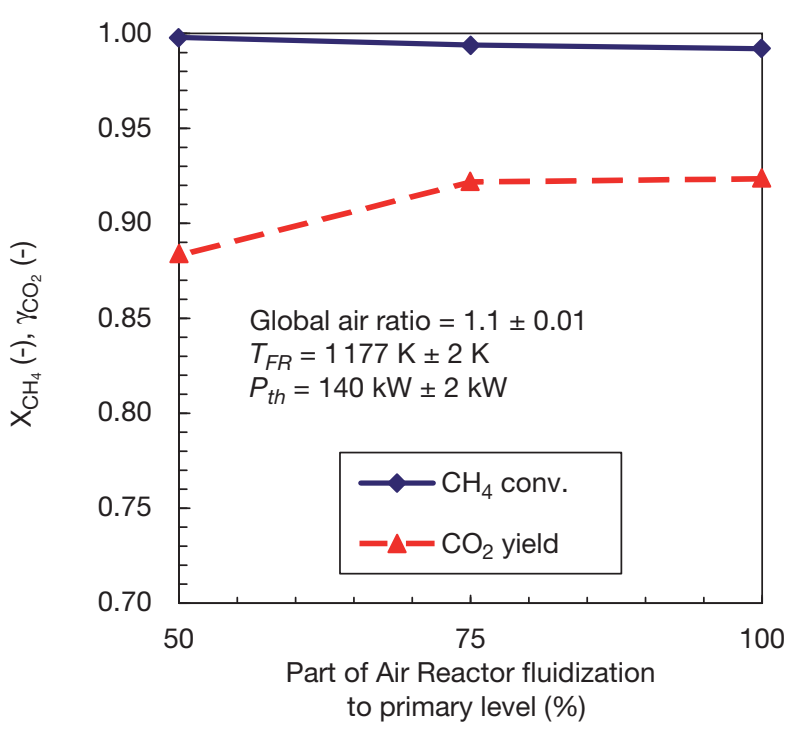

Figure 4

$\mathrm{CH}_{4}$ conversion and $\mathrm{CO}_{2}$ yield during variation of air reactor fluidization level. 
This can be explained by a higher reforming activity of reduced material due to a higher part of free nickel surface. $\mathrm{CO}_{2}$ yield (and thus the conversion of $\mathrm{CO}$ ) is decreasing with decreasing degree of oxidation. It is likely that this reflects a limitation of the particles to supply oxygen fast enough at the more reduced conditions. Generally, the observed fuel conversion behavior is in agreement with theory.

The global solids circulation rate shown in the figures above is calculated from the measured degree of oxidation in both connecting loop seals and from the gas phase mass balances around each of the two reactors. Since the amount of oxygen added to the FR gas stream is known from FR exhaust gas composition and inlet natural gas flow rate, the mass of circulating solids can be calculated from the difference in the degree of oxidation between upper and lower loop seal. The method is described in detail by Kolbitsch et al. [13]. Practically, the calculation is carried out along with the full mass and energy balance evaluation of the operating point using the process simulation model as described by Bolhàr-Nordenkampf et al. [18]. This means that the solids circulation rate is only known after evaluation of the solids samples, what typically takes a few days. Therefore, it was attempted to correlate the horizontal pressure difference across the upper and lower loop seal to the global circulation rate. The horizontal pressure difference was taken from the downcomer and from the rising section of the symmetrically designed loop seals at the same height, about $0.1 \mathrm{~m}$ above the loop seal fluidization level. This means that the mean pressure difference must be zero if no flow of particles passes through the loop seal. If a flow occurs, the pressure difference will be proportional to the friction forces of the particles moving through the horizontal part of the loop seal. The result is shown in Figure 5 for a load variation run where the steam fluidization flow rate to the loop seal was kept constant. Application of this specific correlation allows onlineestimation of the solids circulation rate from simple pressure measurements. Comparison between lower and upper loop seal prediction can reduce uncertainty.

\subsection{Chemical Looping Reforming}

The transition between CLC and CLR is smooth. The FR exhaust gas composition of the FR for an air/fuel ratio variation at a constant FR temperature of $900^{\circ} \mathrm{C}$ is shown in Figure 6. It can be observed that the $\mathrm{CH}_{4}$ conversion (R2) is practically complete for global air/fuel ratios smaller than 1 . With decreasing air/fuel ratio the fractions of $\mathrm{CO}$ and $\mathrm{H}_{2}$ in the FR exhaust gas increase and a synthesis gas is obtained. It was shown that the composition of the FR exhaust gas agrees with the equilibrium of the $\mathrm{CO}$ shift reaction (R6) evaluated at FR temperature [17].

The gas composition leaving the AR is shown for the same variation in Figure 7. The material used is capable to absorb the oxygen quantitatively from the gas stream passing the AR. This means there is a nitrogen/argon stream as potentially valuable by-product of CLR [17].

It is important to notice that no carbon formation could be observed during the CLR test run shown in Figures 6 and 7 even though the steam to organic carbon ratio in the FR feed stream was rather low. In the unlikely worst case assumption that all lower loop seal steam would go to the FR a steam/carbon ratio of only 0.4 is obtained in the lower part of the FR. Carbon formation could be observed in tests not shown here for global air/fuel ratios of 0.4 and below and result in $\mathrm{CO}_{2}$ detected in the AR exhaust gas stream.

Finally, the degree of oxidation of the oxygen carrier leaving AR and FR, respectively, is shown in Figure 8 together with the solids flux through the AR, which is proportional to the global solids circulation rate. It can be observed that the decrease of air supply to the AR (what is expressed by the air/fuel ratio decrease at a constant fuel power) resulted in a significant decrease of the global solids circulation rate. The Air Reactor temperature (not shown in the graphs) increases from $\sim 900^{\circ} \mathrm{C}$ (no significant difference to FR in CLC) to slightly above $1000^{\circ} \mathrm{C}$ when reducing the air/fuel ratio to 0.52 . This is the consequence of the increased heat demand in the FR in case of incomplete oxidation in combination with the decreasing solids circulation rate.

Also, the degree of oxidation of the particles is globally very low in CLR operation. There is also some indication that the particles react slow with respect to their oxidation state: the variation was performed starting with an air/fuel ratio of 1.2 and decreasing then in steps. Likely as a memory of start-up in oxidizing conditions, the degree of oxidation at the beginning was high, even higher than for the CLC cases shown in Figure 3. There seems to be a steep transition to lower values and the dynamic equilibrium with respect to the degree of oxidation is probably reached only for the points of an air/fuel ratio lower than 0.9 .

\section{CONCLUSIONS}

The Dual Circulating Fluidized Bed (DCFB) reactor system works stable and robust with respect to fluid dynamics. The pilot plant was operated using a designed NiO-based oxygen carrier particle.

The following observations can be made for Chemical Looping Combustion (CLC) operation:

- fuel conversion to $\mathrm{CO}_{2}$ and $\mathrm{H}_{2} \mathrm{O}$ is well above $90 \%$;

- a reduced degree of oxidation of the oxygen carrier enhances $\mathrm{CH}_{4}$ conversion but decreases $\mathrm{CO}$ conversion there seems to be a trade-off;

- the solids circulation rate can be correlated to the horizontal pressure difference in the loop seals. 


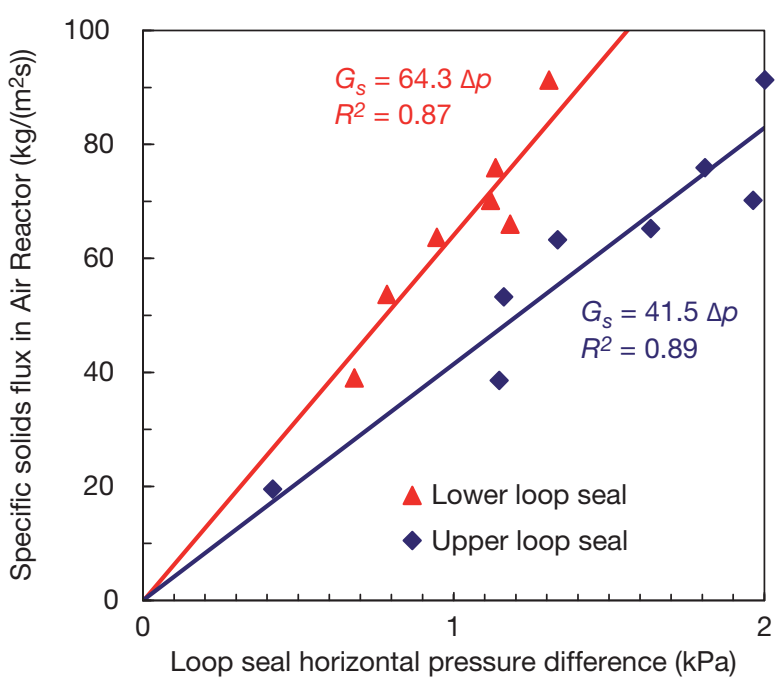

Figure 5

Correlation between loop seal horizontal pressure difference and global solids circulation rate.

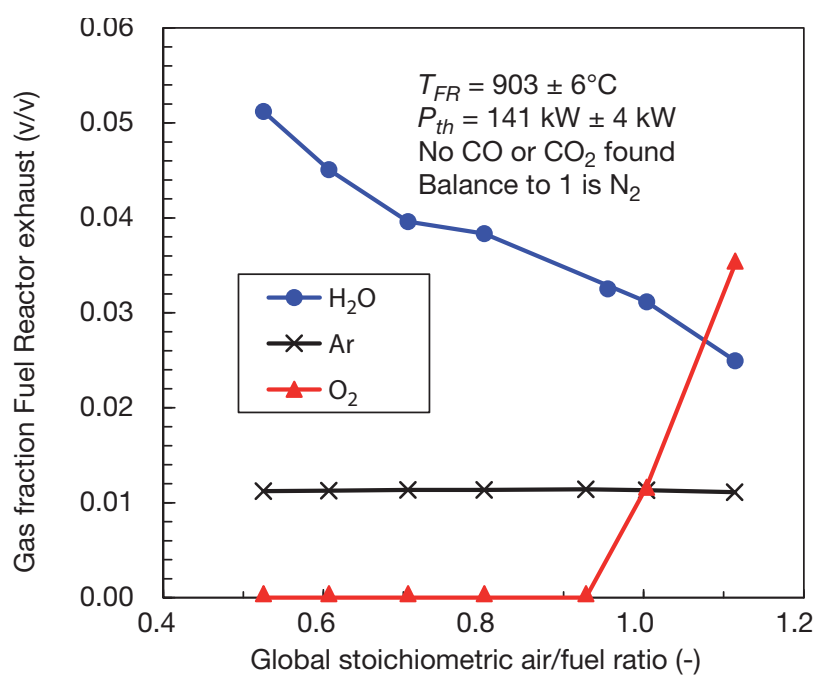

Figure 7

Air Reactor (AR) exhaust gas composition in Chemical Looping Reforming (CLR) operation.

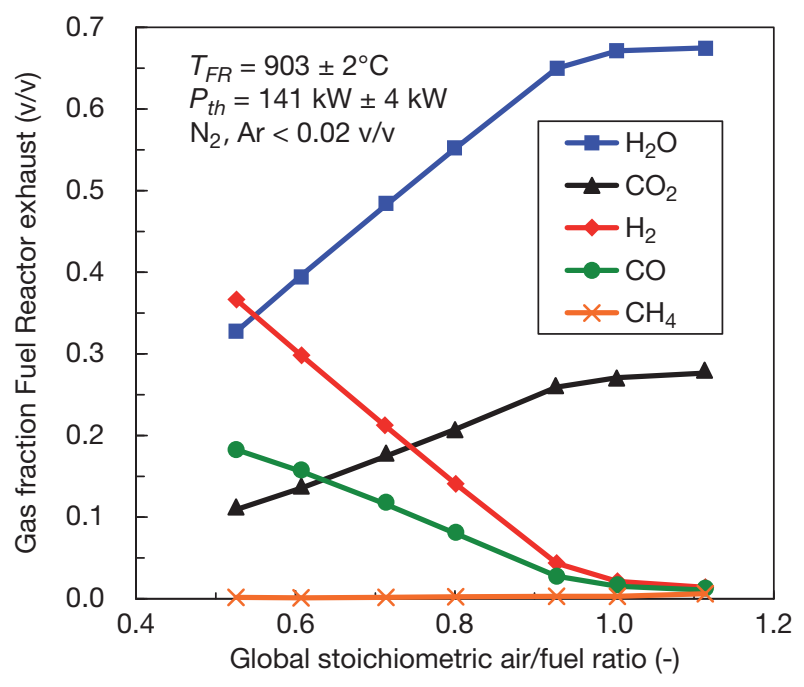

Figure 6

Fuel Reactor (FR) exhaust gas composition in Chemical Looping Reforming (CLR) operation.

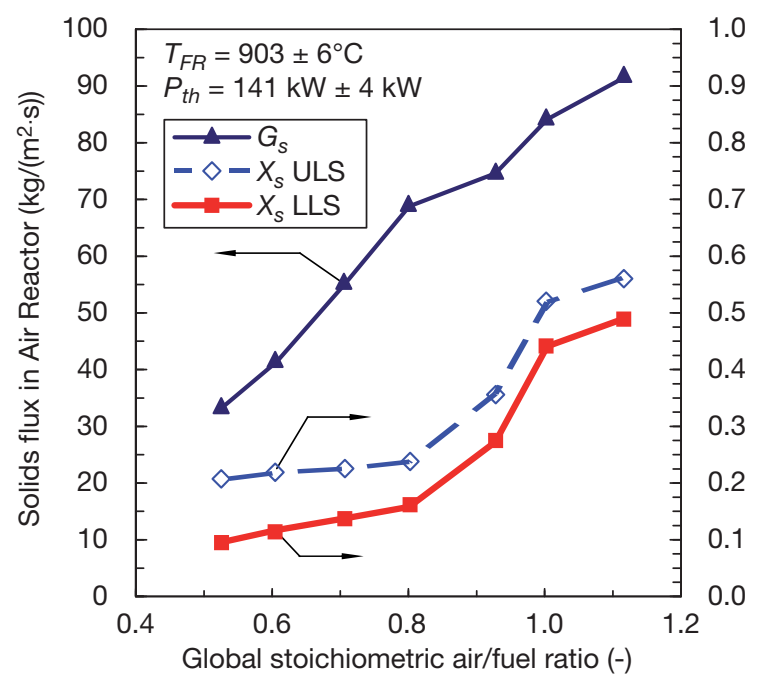

Figure 8

Solids circulation rate and oxygen carrier degree of oxidation in Chemical Looping Reforming (CLR) operation.
From a Chemical Looping Reforming (CLR) test series performed, the following conclusions can be drawn:

- a synthesis gas mixture is obtained which reflects the thermodynamic equilibrium for FR exit temperature and pressure;

- no carbon formation on the particles occurs for global air/ fuel ratios larger than 0.4 and at a steam/carbon ratio of 0.4 ;

- all $\mathrm{O}_{2}$ is absorbed by the particles in the AR and the AR exhaust gas stream consists of $\mathrm{N}_{2}$ and Ar only as soon as the AR temperature is higher than $900^{\circ} \mathrm{C}$.

With respect to further scale up of chemical looping systems it can be concluded that atmospheric pressure systems operated with NiO-based oxygen carriers can be built today. Here, a suitable next scale would be in the range of 10-20 $\mathrm{MW}_{\mathrm{th}}$. Interesting options for such next scale plants could be in the area of industrial steam generation using CLC or in the field of CLR.

\section{ACKNOWLEDGMENTS}

Financial support from the European Commission's 6th Framework Programme is gratefully acknowledged (FP6 Contracts No. 019800 and No. 019972). The joint work on chemical looping was coordinated by Chalmers University of Technology and was also part of Phase II of CCP $\left(\mathrm{CO}_{2}\right.$ Capture Project) through Shell and BP. 


\section{REFERENCES}

1 Lyon R.K., Cole J.A. (2000) Unmixed combustion: An alternative to fire, Combust. Flame 121, 1-2, 249-261.

2 Lyngfelt A. (2010) Oxygen-Carriers for ChemicalLooping Combustion - Operational Experience, Les Rencontres Scientifiques de l'IFP: 1st International Conference on Chemical Looping, Lyon, 2010.

3 Lewis W.K., Gilliland E.R. (1954) Production of pure carbon dioxide, United States Patent No. 2665972.

4 Welty Jr A.B. (1951) Apparatus for conversion of hydrocarbons, United States patent No. 2550741.

5 Knoche K.F., Richter H. (1968) Verbesserung der Reversibilität von Verbrennungsprozessen, Brennst.Wärme-Kraft 20, 205-210 (in German).

6 Ishida M., Jin H. (1997) $\mathrm{CO}_{2}$ recovery in a power plant with chemical looping combustion, Energ. Convers. Manage. 38, Suppl. 1, 187-192.

7 Lyngfelt A., Thunman H. (2004) Chemical-looping combustion: Design, construction and $100 \mathrm{~h}$ of operational experience of a $10 \mathrm{~kW}$ prototype, in Carbon Dioxide Capture for Storage in Deep Geologic Formations Results from the $\mathrm{CO}_{2}$ Capture Project: Vol. 1 - Capture and Separation of Carbon Dioxide from Combustion, Thomas D. (ed.), Elsevier, London, ISBN 0080445705.

8 Ryu H.J., Jin G.T., Yi C.K. (2004) Demonstration of inherent $\mathrm{CO}_{2}$ separation and no NOx emission in a $50 \mathrm{kWth}$ chemical-looping combustor: Continuous reduction and oxidation experiment, in Seventh International Conference on Greenhouse Gas Control Technologies (GHGT-7), pp. 1907-1910.

9 Johansson E., Mattisson T., Lyngfelt A., Thunman H. (2006) Combustion of syngas and natural gas in a $300 \mathrm{~W}$ chemical-looping combustor, Chem. Eng. Res. Des. 84, 9A, 819-827.

10 Adánez J., Gayán P., Celaya J., De Diego L.F., GarcíaLabiano F., Abad A. (2006) Chemical looping combustion in a $10 \mathrm{~kW}$ th prototype using a $\mathrm{CuO} / \mathrm{Al}_{2} \mathrm{O}_{3}$ oxygen carrier: Effect of operating conditions on methane combustion, Ind. Eng. Chem. Res. 45, 17, 6075-6080.

11 Kolbitsch P., Pröll T., Bolhàr-Nordenkampf J., Hofbauer H. (2009) Design of a chemical looping combustor using a Dual Circulating Fluidized Bed (DCFB) reactor system, Chem. Eng. Technol. 32, 3, 398-403.

12 Pröll T., Rupanovits K., Kolbitsch P., BolhàrNordenkampf J., Hofbauer H. (2009) Cold flow model study on a Dual Circulating Fluidized Bed (DCFB) system for chemical looping processes, Chem. Eng. Technol. 32, 3,418-424.

13 Kolbitsch P., Pröll T., Bolhar-Nordenkampf J., Hofbauer H. (2009) Characterization of chemical looping pilot plant performance via experimental determination of solids conversion, Energ. Fuel. 23, 3, 1450-1455.

14 Kolbitsch P., Bolhàr-Nordenkampf J., Pröll T., Hofbauer H. (2009) Comparison of two Ni-based oxygen carriers for chemical looping combustion of natural gas in $140 \mathrm{~kW}$ continuous looping operation, Ind. Eng. Chem. Res. 48, 11, 5542-5547.

15 Pröll T., Kolbitsch P., Bolhàr-Nordenkampf J., Hofbauer H. (2009) A novel Dual Circulating Fluidized Bed (DCFB) system for chemical looping processes, AIChE J. 55, 12, 3255-3266.

16 Kolbitsch P., Bolhàr-Nordenkampf J., Pröll T., Hofbauer H. (2010) Operating experience with chemical looping combustion in a $120 \mathrm{~kW}$ dual circulating fluidized bed (DCFB) unit, Int. J. Greenhouse Gas Cont. 4, 2, 180-185.

17 Pröll T., Bolhàr-Nordenkampf J., Kolbitsch P., Hofbauer H. (2010) Syngas and a separate nitrogen/argon stream via chemical looping reforming - A $140 \mathrm{~kW}$ pilot plant study, Fuel 89, 6, 1249-1256.

18 Bolhàr-Nordenkampf J., Pröll T., Kolbitsch P., Hofbauer H. (2009) Comprehensive Modeling Tool for Chemical Looping Based Processes, Chem. Eng. Technol. 32, 3, 410-417.

19 Lyngfelt A., Leckner B., Mattisson T. (2001) A fluidized bed combustion process with inherent $\mathrm{CO}_{2}$ separation, Application of Chemical Looping Combustion, Chem. Eng. Sci. 56, 10, 3101-3113.

20 Ryu H., Bae D., Jin G. (2002) Chemical-looping combustion process with inherent $\mathrm{CO}_{2}$ separation; Reaction kinetics of oxygen carrier particles and $50 \mathrm{kWth}$ reactor design, in The World Congress of Korean and Korean Ethnic Scientists and Engineers, Seoul, Korea, pp. 738743.

21 Hugi E., Reh L. (1998) Design of cyclones with high solids entrance loads, Chem. Eng. Technol. 21, 9, 716719.

22 Linderholm C., Mattisson T., Lyngfelt A. (2009) Longterm integrity testing of spray-dried particles in a $10 \mathrm{~kW}$ chemical-looping combustor using natural gas as fuel, Fuel 88, 2083-2096.

Final manuscript received in October 2010 Published online in April 2011

Copyright (C) 2011 IFP Energies nouvelles

Permission to make digital or hard copies of part or all of this work for personal or classroom use is granted without fee provided that copies are not made or distributed for profit or commercial advantage and that copies bear this notice and the full citation on the first page. Copyrights for components of this work owned by others than IFP Energies nouvelles must be honored. Abstracting with credit is permitted. To copy otherwise, to republish, to post on servers, or to redistribute to lists, requires prior specific permission and/or a fee: Request permission from Information Mission, IFP Energies nouvelles, fax.+33147527096, or revueogst@ifpen.fr. 